\title{
Aristolochia quangbinhensis (Aristolochiaceae), a new species from Central Vietnam
}

\author{
Truong Van Do ${ }^{1,2}$, Trong Duc Nghiem³ ${ }^{3}$ Stefan Wanke', Christoph Neinhuis' \\ I Institut für Botanik, Technische Universität Dresden, Zellescher Weg 20b, D-01062 Dresden, Germany \\ 2 Vietnam National Museum of Nature, Vietnam Academy of Science \& Technology, 18 Hoang Quoc Viet, Ha- \\ noi, Vietnam 3 Department of Botany, Hanoi University of Pharmacy, 13-15 Le Thanh Tong, Hanoi, Vietnam
}

Corresponding author: Truong Van Do (dovantruong_bttn@yahoo.com)

Academic editor: M. Jaramillo | Received 13 August 2013 | Accepted 13 January 2014 | Published 22 January 2014

Citation: Do TV, Nghiem TD, Wanke S, Neinhuis C (2014) Aristolochia quangbinhensis (Aristolochiaceae), a new species from Central Vietnam. PhytoKeys 33: 51-59. doi: 10.3897/phytokeys.33.6094

\begin{abstract}
Aristolochia quangbinhensis T.V. Do, a new species from Central Vietnam, is described and illustrated. According to morphology, the species belongs to Aristolochia subgenus Isotrema. A detailed description, along with line drawings, photographs, ecology, distribution, conservation status as well as a comparison to morphologically similar species is provided.
\end{abstract}

\section{Keywords}

Aristolochia, Aristolochia quangbinhensis, Aristolochiaceae, Isotrema, new species, Vietnam

\section{Introduction}

Aristolochia comprises about 500 species and is the largest genus of Aristolochiaceae (Wagner et al. 2012). Recent phylogenetic studies of the genus based on morphological and molecular data suggested a subdivision of Aristolochia into three subgenera: Aristolochia, Isotrema and Pararistolochia (Wanke et al. 2006). Aristolochia subgenus Aristolochia occurs from the Mediterranean zone to subtropical and tropical areas of America, Africa and Asia, Aristolochia subgenus Pararistolochia is present in tropical Africa and Australasia, whereas Aristolochia subgenus Isotrema shows a disjunct Asian and Central- and North American distribution (Wanke et al. 2006, Ohi-Toma et al. 2006, González et al. 2013, Buchwalder et al. in press). Aristolochia subgenus Isotrema (hereafter shortened to Isotrema) comprises 
about 70 species, 50 of which occur in Asia (González et al. 2013). In Vietnam two subgenera occur, namely Aristolochia and Isotrema.

Isotrema is well known for its $\mathrm{U}$ - or horseshoe-shaped perianth, the utricle and the tube are not sharply delimited, a strongly folded or curved tube, a 3-lobed limb, sometimes with fused lobes, and a gynostemium consisting of three segments, each of them carrying two anthers on the outer surface. In contrast, subgenus Aristolochia can be recognized by its slightly curved or rectilinear tube, the utricle and the tube are sharply distinct, a one- to three-lobed perianth limb, a gynostemium with more than three lobes, each of them carrying a single anther on the outer surface. Based on these characters, the new species can be easily assigned to subgenus Isotrema.

In an illustrated Flora of Vietnam, Ho (2000) reported 11 species of Aristolochia, including four belonging to Isotrema. Hwang et al. (2003) listed 45 species of Aristolochia for the Flora of China, 33 of which are restricted to this country. In the latter study, 29 Chinese species belong to Isotrema, and only one of them (A. petelotii O.C. Schmidt) was mentioned to occur also in Vietnam, although the floras of southern China and northern Vietnam have many angiosperm species in common. Ban (2003) recorded 13 species and one variety for Vietnam, and listed the same species of Isotrema as those mentioned by Ho (2000), plus A. kwangsiensis W.Y. Chun \& F.C. How ex C.F. Liang. In preparation of a taxonomic revision of Aristolochia for Vietnam, a new Aristolochia species belonging to Isotrema was found in Central Vietnam and is described here.

\section{Methods}

Based on morphological characters, a first overview of the genus Aristolochia from Vietnam and adjacent areas (southern China, Laos, Cambodia \& Thailand) was prepared. All available specimens of Aristolochia housed in Vietnamese herbaria (CPNP, HN, HNU, IMM, VNM VNMN), relevant collections from institutions abroad (DR, HITBC, IBK, IBSC, K, KUN, L, MO, P, SING) and material from recent fieldwork were examined. All morphological characters were studied under dissecting microscopes, and are described using the terminology presented by Harris (2001) \& Hwang et al. (2003).

\section{Taxonomy}

Aristolochia quangbinhensis T. V. Do, sp. nov. urn:Isid:ipni.org:names:77135668-1

http://species-id.net/wiki/Aristolochia_quangbinhensis

Figure 1, 2

Note. This new species is morphologically similar to A. championii Merill \& W.Y. Chun, A. vallisicola T.L. Yao, A. petelotii O.C. Schmidt and A. versicolor S.M. Hwang, but is distinguishable from these species by the following diagnostic characters: petiole 

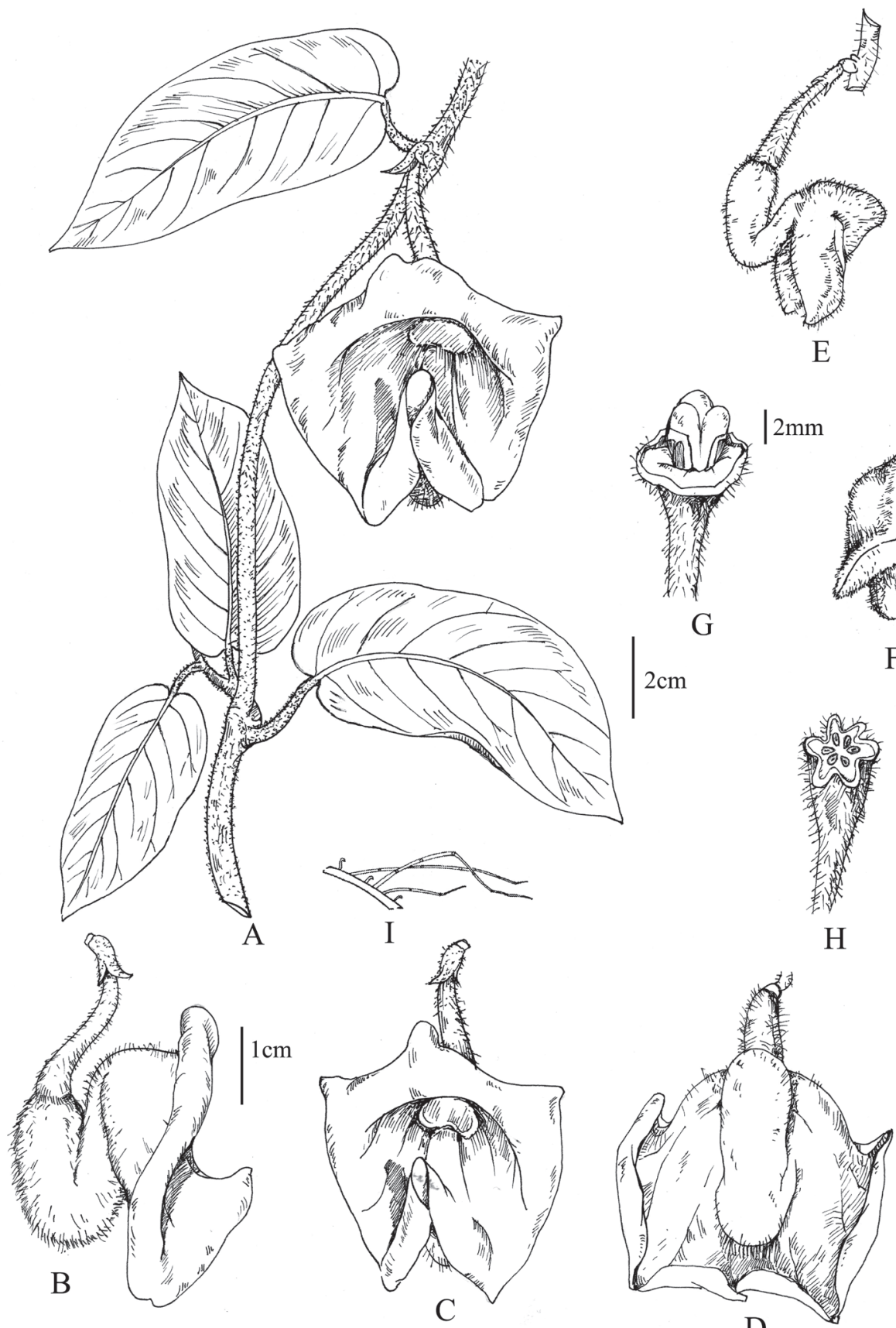

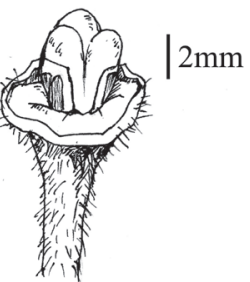

$\mathrm{G}$
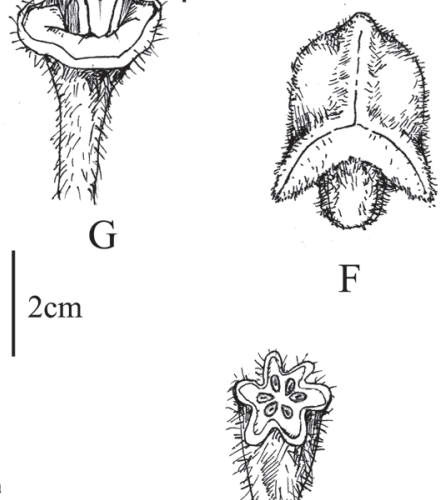

$\mathrm{F}$

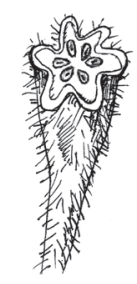

$\mathrm{H}$

Figure I. Line drawing of Aristolochia quangbinhensis T.V. Do. A Flowering branch B-D Lateral (B) frontal $(\mathbf{C})$ and dorsal $(\mathbf{D})$ views of a flower at anthesis E-F Lateral $(\mathbf{E})$ and frontal $(\mathbf{F})$ views of a preanthetic flower $\mathbf{G}$ Gynostemium and ovary $\mathbf{H}$ Transverse section of ovary I Multicellular trichomes on the surface of the petiole. Drawing by N.V. Quyet from the holotype. 
1.5-2.5 (-3) cm long; lamina elliptic to oblong-elliptic; peduncle $1.5-2 \mathrm{~cm}$ long, covered with yellow-brown trichomes; perianth limb bell-shaped, 2-2.5 $(-3) \mathrm{cm}$ wide, exclusively purplish-pink on both sides, no blotches or veins are visible; perianth margins recurved; flower tube mouth slightly darker than the remaining perianth limb; perianth tube pale yellow to whitish and the entire back of the perianth limb and tube covered with yellow-brown trichomes.

Type. VIETNAM. Quang Binh province: Minh Hoa district, Hoa Luong community, $17^{\circ} 47^{\prime} 5.00^{\prime \prime N}, 105^{\circ} 52^{\prime} 20.05^{\prime \prime E}$, elev. 380 m, 3 April 2013, T.V. Do 39 (holotype: VNMN; isotype: DR).

Description. Perennial woody lianas. Roots numerous, fasciculate and cylindrical. Stems terete, densely yellow-brown villous when young, older stems with corky bark, glabrous. Petiole $1.5-2.5(-3) \mathrm{cm}$ long, straight, densely covered with yellow-brown trichomes; lamina elliptic to oblong-elliptic, (6-)8-13(-14) cm long, 3-5(-6) $\mathrm{cm}$ wide, subcoriaceous, base subcordate to auriculate, with a shallow sinus 3-4 mm deep, (1-) 1.5-2 mm wide, apex acute, adaxially glabrous, dark green, abaxially densely yellow-brown villous, basal veins 3 , palmate, secondary veins 7-8 pairs, pinnate, venation densely reticulate and prominent on both sides. Flowers terminal, solitary, but accompanied by a lanceolate scale-like bracteole, (2-)3 $\mathrm{mm}$ long, (1.5-) $2 \mathrm{~mm}$ wide, sessile, inserted near base of the peduncle, conspicuous, persistent. Peduncles $1.5-2 \mathrm{~cm}$ long, pendulous, purple, densely hirsute. Peduncles, bracts and perianth densely covered by yellow-brown pluricellular hairs. Perianth S-shaped, (3-)3.2-3.5 cm long, outside densely yellow-brown hirsute with obscure, parallel veins, inside smooth. Ovary oblong, (0.8-)1-1.2 cm long, $0.3-0.4 \mathrm{~cm}$ diam., yellowish-green, densely hirsute, 6-locular, ovules numerous, usually in one series. Utricle ovoid, (1.2-) $1.5-1.8 \mathrm{~cm}$ long, $0.5-0.6(-0.8) \mathrm{cm}$ diam., externally white, inner surface basally with a dark-purple patch and distally with a white patch; tube strongly curved at its base, parallel and in close contact with the utricle, narrower than the utricle, cylindrical, $0.9-1.0 \mathrm{~cm}$ long, $0.4-0.5 \mathrm{~cm}$ diam.; limb three-lobed, bell-shaped, 2-2.5 (-3) cm diam., purplish-pink on both sides, without any blotches or veins visible, outer surface densely hirsute, inner surface smooth, the three unequal lobes valvate in preanthetic flowers, the lateral lobes broadly deltoid with acute apex, the lower (median) lobe semicircular, during anthesis bell-shaped and with the margins recurved; throat circular, dark-purple, densely papillose; annulus present, formed by an ellipsoid flange, dark-violet; gynostemium three-lobed, lobes with obtuse apices, smooth, (3-) 4-5 mm high, 2-3 mm diam., white; stamens six in one serie of three pairs; anthers oblong, (2-)2.5-3 mm long, yellow, tetralocular, longitudinally dehiscent. Capsules not seen.

Vernacular name. Phòng Kỷ Quảng Bình (in Vietnamese).

Distribution. Aristolochia quangbinhensis is known from a single population found on the north-eastern slope of a mountain range bordering the buffer zone of Phong Nha-Ke Bang National Park in the Hoa Luong community, Minh Hoa district, Quang Binh province (Fig. 3). It might also be present in Laos P.D.R., because of the proximity of the Khammouan province with Central Laos. 


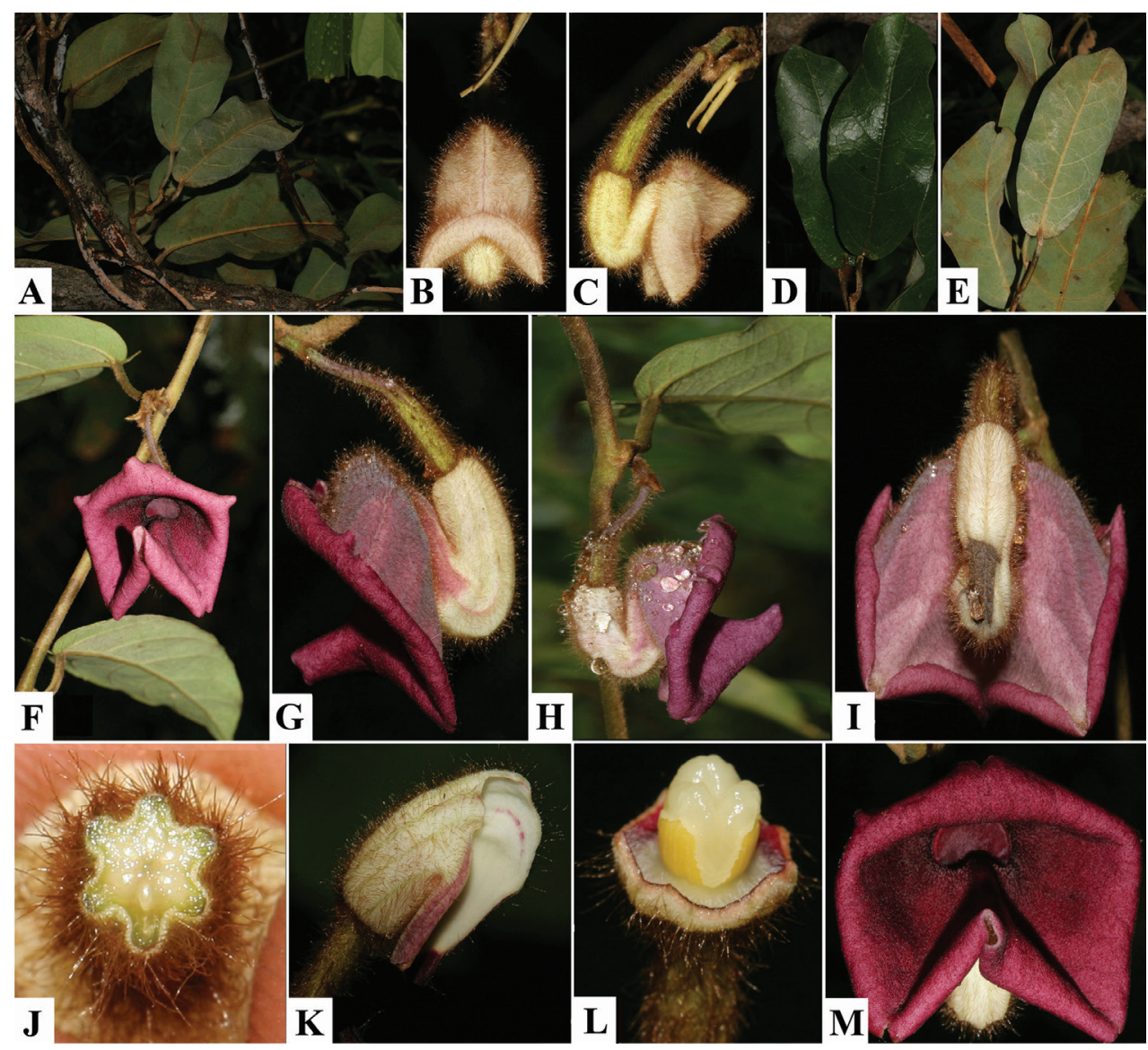

Figure 2. Photographs of Aristolochia quangbinhensis T.V. Do. A Habit B-C Frontal (B) and lateral (C) views of a preanthetic flower D-E Leaf in adaxial (D) and abaxial (E) views $\mathbf{F}$ Flowering branch $\mathbf{G}-\mathbf{I}$ Lateral (G-H) and dorsal (I) views of flowers at anthesis J Transverse section of the ovary $\mathbf{K}$ Inner surface of perianth $\mathbf{L}$ Gynostemium and ovary $\mathbf{M}$ Frontal view of an anthetic flower. Photographs taken on the holotype locality in Hoa Luong community, Minh Hoa district, Quang Binh province, Central Vietnam.

Ecology. Aristolochia quangbinhensis occurs in humid mountain sites, in the understory of disturbed lowland evergreen broad-leaved forest and mainly evergreen scrubs. Dominant plants at the type locality are Annonaceae (Desmos spp.), Apocynaceae (Marsdenia spp., Wrightia spp.), Fabaceae (Millettia spp.), Lauraceae (Machilus spp., Litsea spp.), Malvaceae (Sterculia spp.), Pandaceae (Microdesmis spp.), Phyllanthaceae (Antidesma spp., Aporosa spp., Glochidion spp.), and Rubiaceae (Randia spp.).

Phenology. Flowering specimens have been collected in April and May but it is possible that blooming already begins in March.

Etymology. The specific epithet refers to the type locality.

Conservation status. In the past, large areas of primary, broad-leaved, evergreen forest covered the Hoa Luong community. Excessive logging, however, resulted in 


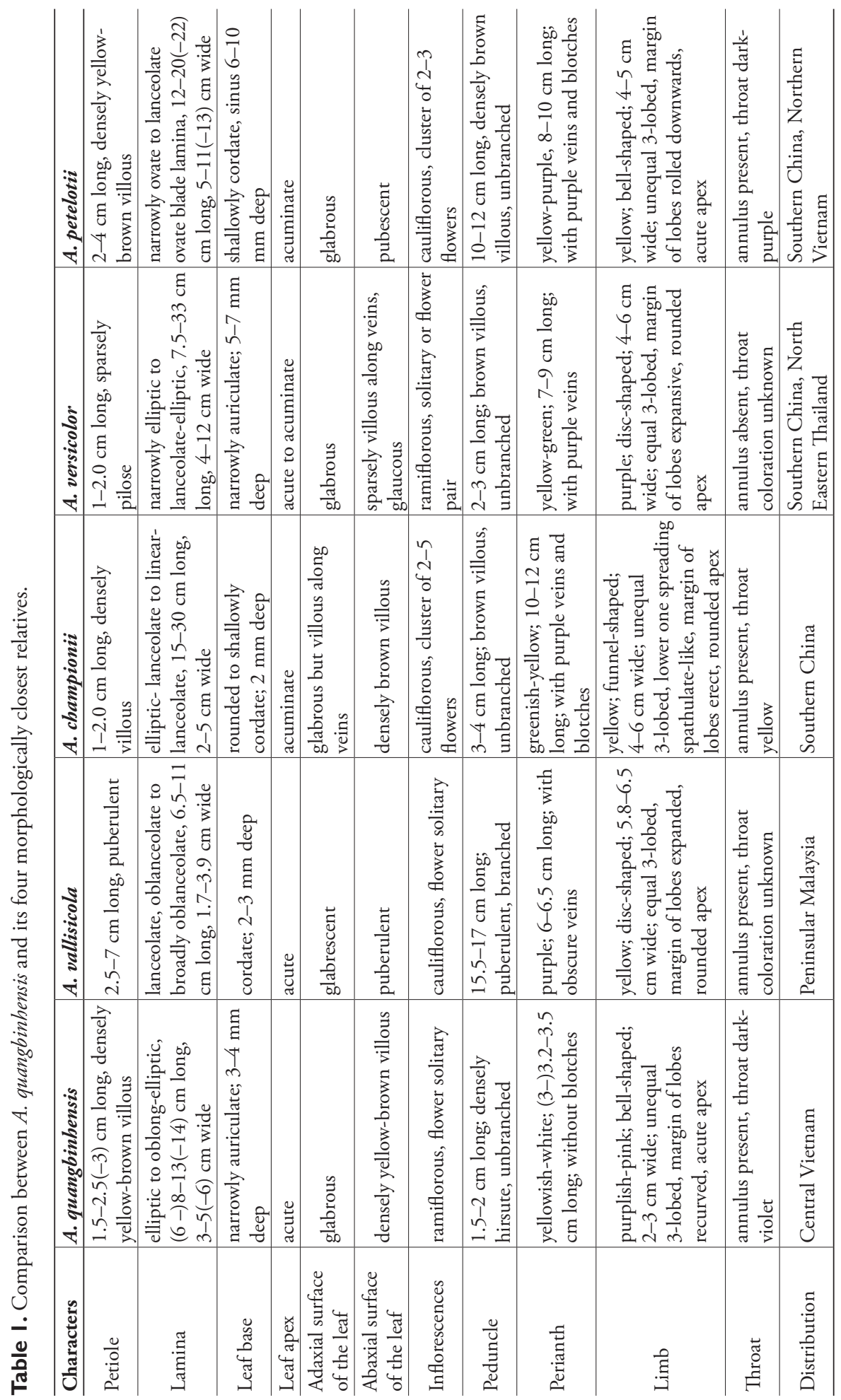




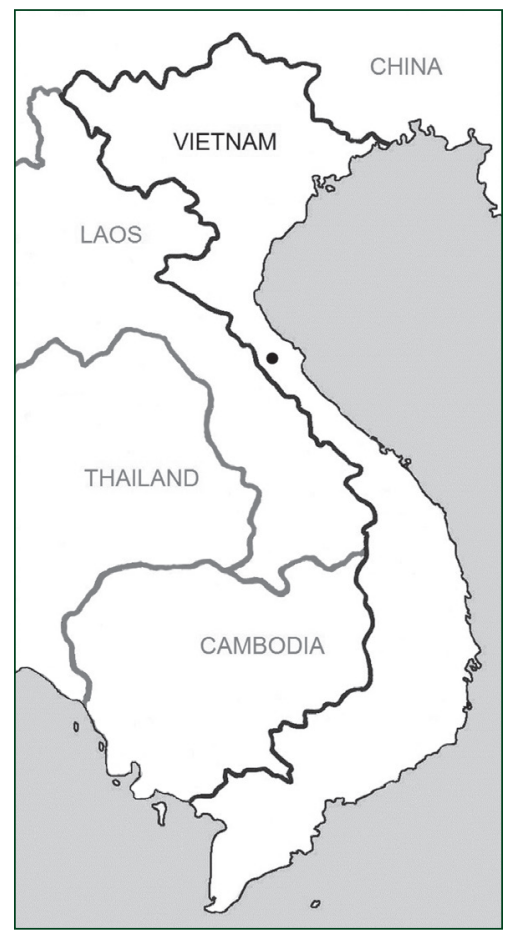

Figure 3. Distribution (dot) of Aristolochia quangbinhensis T.V. Do in Central Vietnam.

the loss of large extensions of primary forest. Although logging was prohibited in the 1990 s, local farmers continued to impose strong pressure on the remaining forest patches converting it mostly into corn and soybean fields. As a result, the flora of the area should be regarded as threatened by extinction. Within the area, $A$. quangbinhensis is known from a single population; in fact, during the present study, only two healthy individuals were located growing about $50 \mathrm{~m}$ apart from each other. Therefore, the new species is assigned a preliminary status of vulnerable (VU D2) according to IUCN Red List criteria (IUCN 2013), indicating a population with a very restricted area of occupancy (typically less than $20 \mathrm{~km}^{2}$ ) or the number of locations (typically five or fewer) being both at hand for $A$. quangbinhensis. The lack of data currently does not allow a final risk evaluation, but the species might also be regarded as endangered (EN).

\section{Discussion}

Aristolochia quangbinhensis is morphologically similar to A. vallisicola T.L. Yao (reported from Pahang, Peninsular Malaysia), A. championii Merr. et Chun (known from Guangdong, Guangxi, China), A. versicolor S.M. Hwang (reported from China and Thailand) and $A$. petelotii O.C. Schmidt (reported from Vietnam and China). However, the new species differs from the aforementioned species by several important veg- 
etative and reproductive characters (summarized in Table 1). This new discovery, along with several new species recently described from Thailand (González and Poncy 1999, Phuphathanaphong 2006), Hainan Island, China (Han Xu et al. 2011), and Peninsular Malaysia (Yao 2012), provide evidence that the genus Aristolochia and in particular Aristolochia subgenus Isotrema is very diverse in South-East Asia. A detailed investigation of the different flower phenotypes and inflorescence between Asian, North and Central American Isotrema species is needed to reconstruct the evolution of floral forms between the biogeographic areas.

\section{Acknowledgements}

We thank the Vietnam National Museum of Nature (VAST) and the curators of the following herbaria for permission to study specimens: CPNP, DR, HITBC, HN, HNU, IBK, IBSC, IMM, K, KUN, L, MO, P, SING, VNM, VNMN. The first author is supported by the Erasmus Mundus program to enroll the $\mathrm{PhD}$ at the TU Dresden. Field work and visits to Chinese herbaria were funded through a DAAD PPP China grant to SW. We also express our sincere thanks to Mr. Quyet, Hanoi for line drawings. We very much appreciate comments and corrections by Favio González (National University of Colombia, Bogotá), and an anonymous reviewer, as well as by the editorial board. Marie-Stéphanie Samain (INECOL, Mexico) is acknowledged for final proofreading.

\section{References}

Ban NT (2003) Checklist of plant species of Vietnam. Agriculture Publishing House, Hanoi, 2: $123-126$.

Buchwalder K, Samain M-S, Sankowsky G, Neinhuis C, Wanke S (in press) Nomenclatural updates of Aristolochia subgenus Pararistolochia (Aristolochiaceae). Australian Systematic Botany. González F, Poncy O (1999) A new species of Aristolochia (Aristolochiaceae) from Thailand. Brittonia 51: 452-456. doi: 10.2307/2666529

González F, Stevenson DW (2002) A phylogenetic analysis of the subfamily Aristolochioideae (Aristolochiaceae). Revista de la Academia Colombiana de Ciencias 26: 25-60.

González F, Wagner ST, Salomo K, Symmank L, Samain MS, Isnard S, Rowe NK, Neinhuis C, Wanke S (2013) Present trans-Pacific disjunct distribution of Aristolochia subgenus Isotrema (Aristolochiaceae) was shaped by dispersal, vicariance and extinction. Journal of Biogeography. doi: 10.1111/jbi.12198

Harris JG (2001) Plant Identification Terminology: An Illustrated Glossary, Spring Lake Publishing, Utah, USA. $2^{\text {nd }}$ edit. 216 pp.

Ho PH (2000) An Illustrated Flora of Vietnam. Young publishing house, Tp. Ho Chi Minh 3: 302-305.

Hou D (1984) Aristolochiaceae. Flora Malesiana, ser. I, 10: 53-108. 
Huber H (1993) Aristolochiaceae. In: Kubitzki K, Rohwer JG, Bittrich V (Eds) The families and genera of vascular plants, Springer, Berlin, 129-137.

Hwang SM (1987) Aristolochiaceae. In: Chen FH, Wu TL (Eds) Flora of Guangdong, Guangdong Science and Technology Press, Guangzhou, 47-62.

Hwang SM (1988) Aristolochiaceae. In: Kiu HS, Ling YR (Eds) Flora Reipublicae Popularis Sinicae, Science Press Beijing, vol. 24.

Hwang SM, Kelly LM, Gilbert MG (2003) Aristolochiaceae. In: Wu ZY, Peter HR (Eds) Flora of China, Science Press Beijing, and Missouri Botanical Garden Press, St. Louis, vol. 5: 246-269.

IUCN (2013) Red List of Threatened Species, Version 2013.1. www.iucnredlist.org [accessed on 26 September 2013]

Lecomte H (1910) Aristolochiaceae. In: Lecomte H (Ed) Flore Général de l'Indo-Chine 4: 57.

Liang CF (1975) The Aristolochiaceae of Kwangsi flora. Acta Phytotaxonomica Sinica. Paris $13(2): 15$.

Ma JS (1989) A revision of Aristolochia Linn. from E. \& S. Asia. Acta Phytotaxonomica Sinica 27(5): 321-364.

Neinhuis C, Wanke S, Hilu KW, Müller K, Borsch T (2005) Phylogeny of Aristolochiaceae base on parsimony, likelihood, and Bayesian analyses of trnL-trnF sequences. Plant Systematics and Evolution 250: 7-26. doi: 10.1007/s00606-004-0217-0

Ohi-Toma T, SugawaraT, Murata H, Wanke S, Neinhuis C, Murata J (2006) Molecular phylogeny of Aristolochia sensu lato (Aristolochiaceae) based on sequences of rbcL, matK, and phyA genes, with special reference to differentiation of chromosome numbers. Systematic Botany 31: 481-492. doi: 10.1600/036364406778388656

Phuphathanaphong L (2006) New taxa of Aristolochia (Aristolochiaceae) from Thailand. Thai Forest Bulletin (Botany) 34: 179-194.

Wagner ST, Isnard S, Rowe NP, Samain MS, Neinhuis C, Wanke S (2012) Escaping the lianoid habit: evolution of shrub-like growth forms in Aristolochia subgenus Isotrema (Aristolochiaceae). American Journal of Botany 99(10): 1609-1629. doi: 10.3732/ajb.1200244

Wanke S, González F, Neinhuis C (2006) Systematics of pipevines: combining morphologi$\mathrm{cal}$ and fast-evolving molecular characters to investigate the relationships within subfamily Aristolochioideae (Aristolochiaceae). International Journal of Plant Sciences 167 (6): 1215-1227. doi: 10.1086/508024

Xu Han, Li YD, Yang HJ, Chen HQ (2011) Two new species of Aristolochia (Aristolochiaceae) from Hainan Island, China. Novon 21: 285-289. doi: 10.3417/2009116

Yao TL (2012) Aristolochia vallisicola (Aristolochiaceae), a new species from Peninsular Malaysia. Phytokeys 14: 15-22. doi: 10.3897/phytokeys.14.3354 